05

\title{
Температурный фактор в управлении деформационно-силовыми свойствами кольцевых силовых пучковых элементов из сплава TiNi
}

\author{
() Ю.Н. Вьюненко, ${ }^{1}$ Г.А. Волков, ${ }^{2}$ Е.А. Хлопков ${ }^{3}$ \\ ${ }^{1}$ ООО „ОПТИМИКСТ лтД“, \\ 195426 Санкт-Петербург, Россия \\ ${ }^{2}$ Институт проблем машиноведения РАН, \\ 199178 Санкт-Петербург, Россия \\ ${ }^{3}$ Санкт-Петербургский политехнический университет Петра Великого, \\ 194021 Санкт-Петербург, Россия \\ email: hlopkovelisey@mail.ru
}

(Поступило в Редакцию 15 февраля 2017 г.)

Показана возможность регулирования деформационно-силовых свойств кольцевых конструкций выбором температурных интервалов работы. Одинаковое механическое воздействие на „металлические мышцы“ при разных температурах привело к значительным изменениям их силовых возможностей. Использована проволока диаметром $2 \mathrm{~mm}$ из сплава Ti-Ni 50.6 at.\%.

DOI: $10.21883 /$ JTF.2018.08.46309.2207

Работа кольцевых силовых пучковых элементов (КСПЭ) в установках, действующих на эффекте памяти формы, далее - установки „ШеР“, показала перспективность использования „металлических мышц“ в технологических процессах [1]. Однако во время наблюдения за поведением силовых элементов в технологических операциях были замечены некоторые особенности в развитии деформационных процессов в области температур мартенситных превращений, претерпеваемых материалом кольцевого силового пучкового элемента (КСПЭ). В условиях силового взаимодействия металлических мышц с обрабатываемыми изделиями при нагреве наблюдается формоизменение, направленное противоположно эффекту памяти формы [2]. Это явление зависит от скорости изменения температуры [3]. Кроме этого фактора на деформационно-силовые характеристики металлических мышц оказывают влияние их химический состав [4], уровень начального силового взаимодействия с обрабатываемым объектом или контртелом [2], режимы термомеханической обработки КСПЭ [5]. Перечисленные взаимозависимости могут быть использованы для разработки способов управления поведением силовых элементов.

В работах [6-8] представлены результаты исследования деформационных свойств образцов из никелида титана при частичном переходе материала из мартенситного состояния в аустенитное или в обратном направлении. Авторы работы добивались этого остановкой нагрева (или охлаждения) при различных температурах внутри интервала превращения, что приводило к изменению деформационных эффектов. Следствием анализа приведенных данных в работах [6-8] результатов стала гипотеза о возможности использования частичного мартенситного превращения в качестве фактора, управляющего работой металлических мышц. Для проверки данного предположения была проведена серия опытов по определению деформационно-силовых характеристик КСПЭ при развитии эффекта памяти формы во время термоциклирования с различной степенью перевода материала силовых элементов в мартенситное состояние.

Конструкция металлических мышц в виде КСПЭ представляет собой бухту, состоящую из нескольких витков. Форма витков может быть различной. Эллиптический вариант конструкции представлен на рис. 1. Исследование деформационно-силовых характеристик проводили на динамометре ЛИНД, схематически представленном на рис. 2. Поскольку в технологических устройствах типа ШеР используется пара металлических мышц, в ЛИНД проводится испытание двух силовых элементов ( 1 , рис. 2$)$, расположенных симметрично относительно контртела (2, рис. 2) в параллельных плоскостях, одновременно.

Силовое воздействие на металлические мышцы регулировали степенью сжатия контртела, которое определялось изменением расстояния между подвижными пластинами (3, рис. 2). Необходимо отметить, что после достижения требуемого уровня сопротивления контрте-

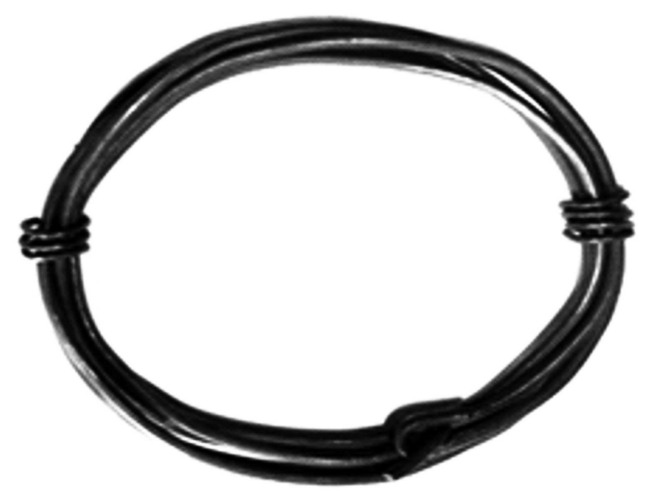

Рис. 1. Внешний вид КСПЭ. 




Рис. 2. Схема нагружения КСПЭ в динамометре ЛИНД: 1 - КСПЭ, 2 - контртело (спиральная пружина), 3 подвижные пластины, 4 - характеристический размер.

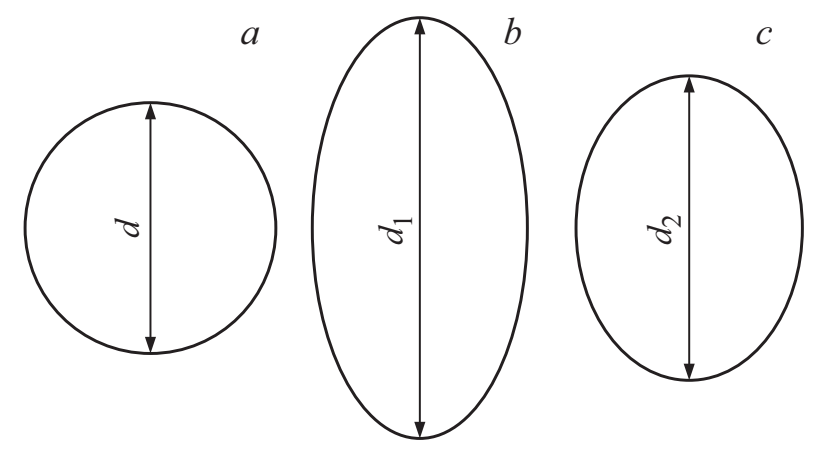

Рис. 3. Состояния КСПЭ: $a-$ исходный размер, $b-$ форма КСПЭ после начального деформирования, $c-$ форма КСПЭ в результате эволюции ЭПФ.

ла нижняя пластина жестко фиксировалась. Температурную зависимость деформационно-силовых параметров определяли, нагревая ЛИНД в термостате. В проведенных опытах температуру варьировали от 293 до $403 \mathrm{~K}$. Охлаждение до 279 и $271 \mathrm{~K}$ проводили в холодильных камерах.

Исследованные силовые элементы изготовлены из проволоки диаметром $2 \mathrm{~mm}$. Конструкция КСПЭ состояла из пяти круговых витков с внутренним диаметром $63 \mathrm{~mm}$. Материал проволоки - сплав TiNi 50.6 at.\%. Предварительно силовые элементы отработали в 33 технологических операциях. Это было сделано для стабилизации температурных интервалов прямого и обратного превращений $[9,10]$.

Металлические мышцы устанавливали в ЛИНД при комнатной температуре после нагрева в свободном состоянии до $403 \mathrm{~K}$ и охлаждения до $271 \mathrm{~K}$. В динамометре КСПЭ и контртело приводили в состояние силового взаимодействия. При этом происходило деформирование силовых элементов. На рис. 3 схематически показаны исходная круговая форма металлических мышц $(a)$, приобретаемая в результате начального деформирования форма вытянутого овала $(b)$ и эволюционирующий в процессе эффекта памяти формы при нагреве овал, промежуточных геометрических параметров $(c)$. Во всех экспериментах режим нагрева был постоянным. Зависимость температуры от времени приведена на рис. 4. Охлаждение силовых элементов вместе с ЛИНД проводили в изотермических условиях холодильных камер. При минимальной температуре металлические мышцы выдерживали не менее $10 \mathrm{~h}$. В этих температурных условиях наращивали силовое воздействие на КСПЭ и выполняли следующий термоцикл. Во время нагрева следили за изменением величины $\Delta=d_{1}-d_{2}$ (рис. 3), что позволило оценивать формовосстановление, обусловленное ЭПФ, и генерацию усилий металлическими мышцами. При повышении силового воздействия на КСПЭ перед нагревом увеличивается значение $d_{1}$. Вторая стадия возрастания этой величины отмечена в термоцикле во время охлаждения. После реализации эффекта памяти формы при нагреве в процессе пони-

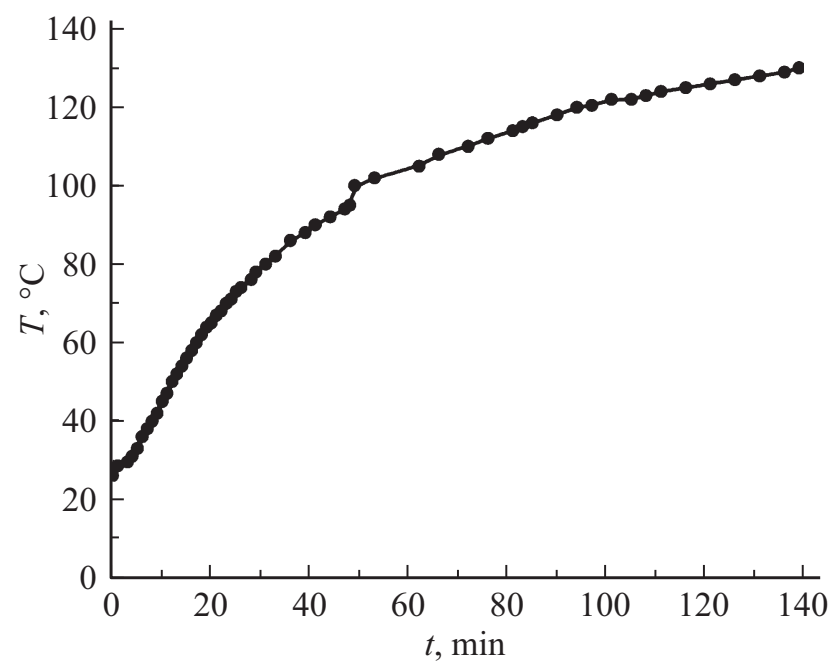

Рис. 4. Режим нагрева термостата во время наблюдения за деформационными процессами.

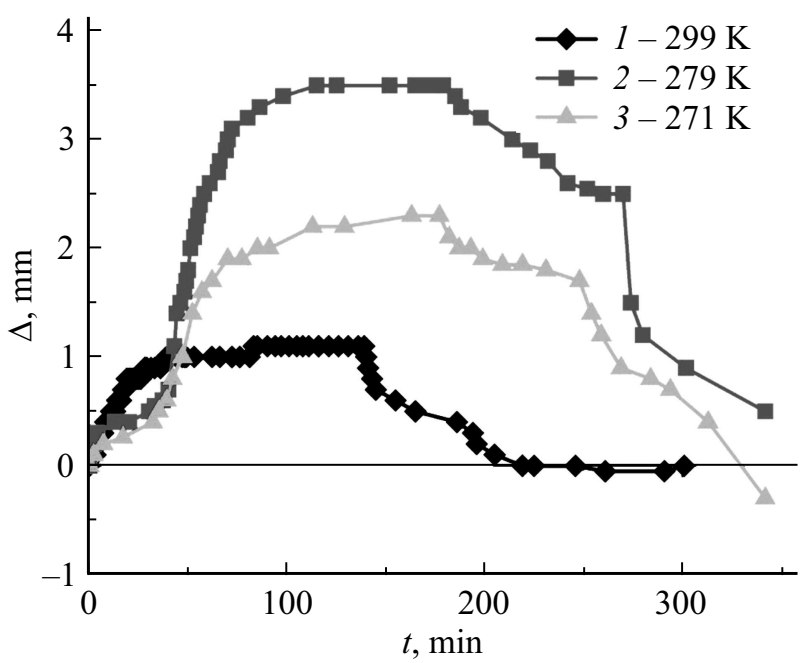

Рис. 5. Развитие деформационных процессов в течение времени при термоциклировании с начальной нагрузкой на КСПЭ $\sim 250 \mathrm{~N}$ и температурах предварительного формоизменения: $1-299,2-279,3-271 \mathrm{~K}$. 


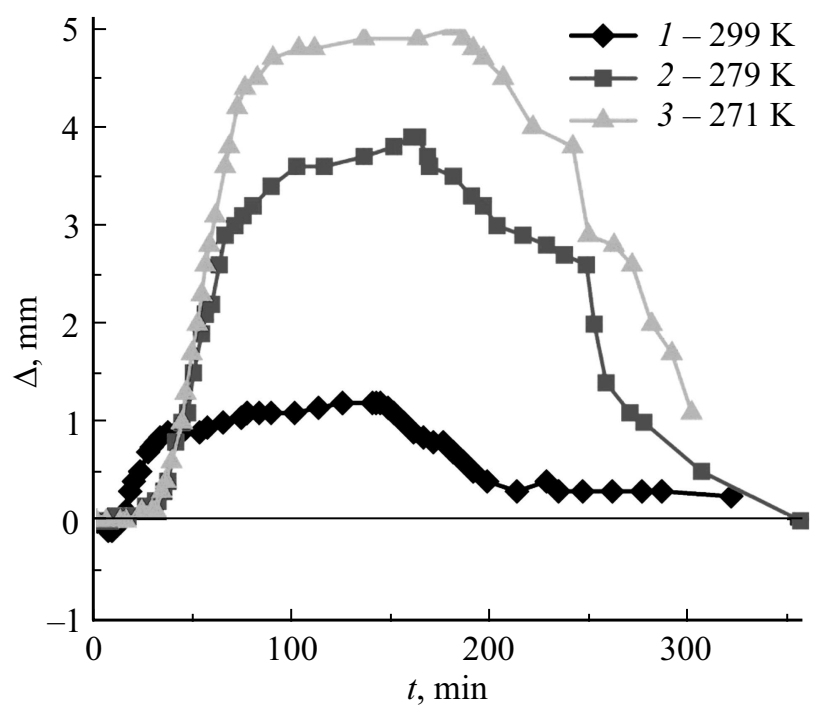

Рис. 6. Развитие деформационных процессов в течение времени при термоциклировании с начальной нагрузкой на КСПЭ $\sim 430 \mathrm{~N}$ и температурах предварительного формоизменения: $1-299,2-279,3-271 \mathrm{~K}$.

жения температуры до интервала прямого превращения материал силовых элементов оказывается в состоянии, свойством которого является пластичность превращения. Это позволяет контртелу не только восстановить значение $d_{1}$, но и, как правило, заметно его увеличить.

Графики на рис. 5 иллюстрируют развитие деформационных процессов при силовом взаимодействии КСПЭ с контртелом на уровне $250 \mathrm{~N}$. Аналогичные кривые для уровня силового контакта в $430 \mathrm{~N}$ приведены на рис. 6. Кривые 1 на рис. 5 и 6 показывают изменение во времени $\Delta$ при минимальной температуре термоцикла в $299 \mathrm{~K}$. В отличие от двух других температурных интервалов термоциклирования в данном случае деформационные процессы начинаются одновременно с нагревом установки ЛИНД в термостате при силе противодействия $250 \mathrm{~N}$ и при $430 \mathrm{~N}$. Различие в изменении параметра $\Delta$ при нагреве для этих опытов невелико. Деформационные эффекты формовосстановления КСПЭ на этапе повышения температуры от $279 \mathrm{~K}$ (кривые 2, рис. 5 и 6) и от $271 \mathrm{~K}$ (кривые 3 , рис. 5 и 6) существенно больше. А процесс интенсивного деформирования начинается через 20-30 min после начала нагрева. При силовом взаимодействии с контртелом $250 \mathrm{~N}$ на этапе роста температуры от $271 \mathrm{~K}$ в результате эффекта памяти формы $\Delta$ достигает величины $2.3 \mathrm{~mm}$ (кривая 3, рис. 5). В аналогичной ситуации после деформирования КСПЭ при $279 \mathrm{~K}$ значение $\Delta$ достигает $3.5 \mathrm{~mm}$ (кривая 2, рис. 5). Иное соотношение параметров формовосстановления наблюдается при силовом контакте металлических мышц и контртела $430 \mathrm{~N}$. При нагреве силовых элементов от $279 \mathrm{~K}$ максимальное значение $\Delta$ равно $4 \mathrm{~mm}$ (кривая 2, рис. 6). А после деформирования КСПЭ при $271 \mathrm{~K}$ отогрев приводит к росту $\Delta$ до $5 \mathrm{~mm}$ (кривая 3, рис. 6). Таким образом, при меньшем усилии противодействия развитию эффекта памяти формы нагрев от $279 \mathrm{~K}$ дает большую степень восстановления формы по сравнению с термоциклом, имеющим минимальную температуру $271 \mathrm{~K}$. А при усилии $\sim 430 \mathrm{~N}$ соотношение значений $\Delta$ противоположное.

В отличие от исследований, проводимых на традиционных образцах, деформирование металлических мышц данной конструкции вызывает индивидуальное распределение полей напряжений и деформаций почти в каждом проволочном сечении. Видимо и соотношение аустенитной и мартенситной фаз во всех трех случаях различно. При 299 К по данным, приведенным в [11], материал может находиться полностью в аустенитном состоянии. В пользу этого можно привести зависимости $d_{1}$ от



Рис. 7. Взаимозависимость размера $d_{1}$ и растягивающего усилия $F$ в условиях изотермического деформирования КСПЭ: $1-403,2-299,3-279,4-271 \mathrm{~K}$.

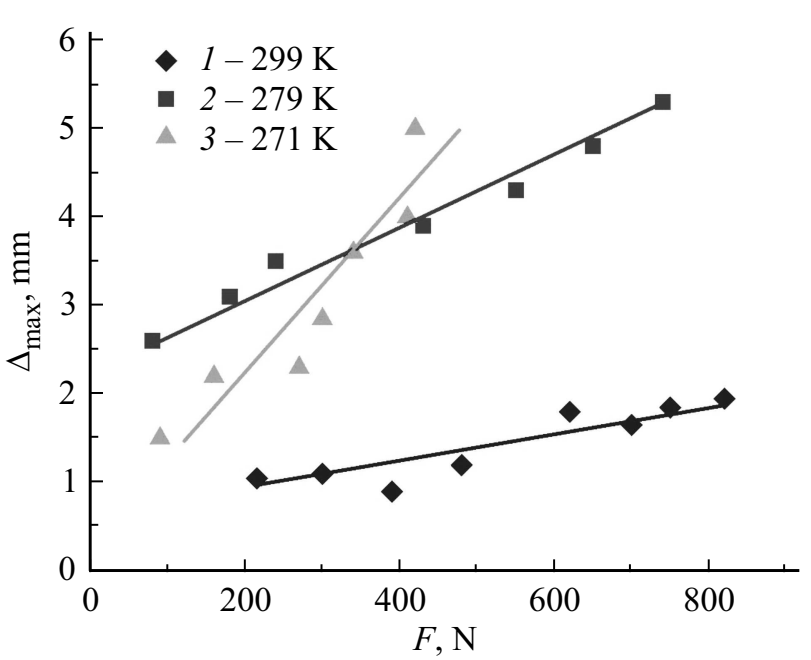

Pис. 8. Зависимость максимального смещения $\Delta$, обусловленного ЭПФ, от начального силового взаимодействия с контртелом $F$ в результате нагрева КСПЭ от температур приложения нагрузки: $1-299,2-279,3-271 \mathrm{~K}$. 
приложенной силы $F$, полученные в изотермических условиях (рис. 7). Кривая 1 на рис. 7 показывает почти линейную взаимозависимость $F$ и $d_{1}$ при $403 \mathrm{~K}$. Близким к линейному является и соотношение этих параметров при $299 \mathrm{~K}$. При этом отклонение от линейности до $F=550 \mathrm{~N}$ заметнее, чем при $403 \mathrm{~K}$ и больших значениях силы. Однако при $299 \mathrm{~K}$ коэффициент пропорциональности линейной зависимости $F$ от $d_{1}$ почти в 2 раза меньше. Это может быть результатом „дефекта“ модуля упругости, отмечаемого в никелиде титана вблизи температур превращения [12]. Аналогичные, близкие к линейным зависимостям, соотношения сил и формоизмения пружины получены в работе [13].

В отличие от первых двух кривых, указывающих на высокотемпературное состояние материала, графики, отражающие соотношение $F$ и $d_{1}$ при температурах $279 \mathrm{~K}$ (кривая 3, рис. 7) и $271 \mathrm{~K}$ (кривая 4, рис. 7), оказались намного сложнее. Участки взаимосогласованного роста $d_{1}$ и $F$ чередуются с наличием „Площадок текучести“, когда $d_{1}$ увеличивается при почти постоянном значении $d_{1}$. Их можно наблюдать на кривой 3 (рис. 7) при $F \sim 250$ и при 590 N. На кривой 4 (рис. 7) такой участок отмечается при $F \sim 440$ N. По-видимому, наличие такой площадки текучести при $F \sim 250 \mathrm{~N}$ привело к тому, что в аналогичном силовом взаимодействии КСПЭ с контртелом формовосстановление после деформирования при $279 \mathrm{~K}$ оказывается значительней эффекта, полученного после нагружения силовых элементов при $271 \mathrm{~K}$. Такое соотношение деформационных эффектов сохраняется до уровня начального силового воздействия на КСПЭ в $330 \mathrm{~K}$ (кривая 2, рис. 8). Дальнейший рост начальной нагрузки на ,металлические мышцы“ приводит к тому, что формовосстановление при нагреве от $271 \mathrm{~K}$ становится больше (кривая 3, рис. 8). Кривая 1 на рис. 8 показывает, что при нагружении КСПЭ при $299 \mathrm{~K}$ деформационный эффект варьирует от 1 до $1.8 \mathrm{~mm}$. Таким образом, генерация дополнительного усилия варьирует от 100 до $175 \mathrm{~N}$. Это может быть использовано в технологических процессах, требующих строгого ограничения силового воздействия на обрабатываемые объекты. Приведенные результаты показывают также возможность разработки приводов и силовых конструкций, использующих дефект модулей упругости. Таким образом, полученные данные показывают эффективность управления деформационносиловыми параметрами металлических мышц выбором условий подготовки их к работе в области температур прямого мартенситного перехода.

\section{Список литературы}

[1] Вьюненко Ю.Н. // В сб.: Перспективные материалы и технологии. Витебск: УО ВГТУ, 2011. С. 182-184.

[2] Тихомиров А.А., Артемьев И.В., Вьюненко Ю.Н. // В сб.: XXI Петербургские чтения по проблемам прочности. СПб.: Соло, 2014. С. 248-250.
[3] Вьюненко Ю.Н. // В сб.: Перспективные материалы и технологии. Витебск: УО ВГТУ, 2015. С. 291-293.

[4] Вьюненко Ю.Н. // Вест. Тамб. ун-та. Серия: Естественные и технические науки. 2013. Т. 18. Вып. 4. С. 2023-2024.

[5] Вьюненко Ю.Н. // Вест. Тамб. ун-та. Серия: Естественные и технические науки. 2016. Т. 21. Вып. 3. С. 791-794.

[6] Паскаль Ю.И., Монасевич Л.А. // ФММ. 1981. Т. 52. Вып. 5. C. 1011-1016.

[7] Беляев С.П., Демина М.Ю., Курзенева Л.Н. // Вест. Тамб. ун-та. Серия: Естественные и технические науки. 1998. T. 3. Вып. 3. С. 300-301.

[8] Беляев С.П., Реснина Н.Н., Аншукова К.О. // Письма в ЖТФ. 2013. Т. 39. Вып. 6. С. 26-32.

[9] Лотков А.И., Гришков В.Н., Анохин С.В., Кузнецов А.В. // Известия вузов. Физика. 1982. Т. 25. Вып. 10. С. 11-16.

[10] Miyazaki S., Igo Y., Otsuka K. // Acta Metall. 1986. Vol. 34. P. 2045-2051.

[11] Корнилов И.М., Качур Е.В., Белоусов О.К. // ФММ. 1971. Т. 32. Вып. 2. С. 420- 421.

[12] Вьюненко Ю.Н., Крылов Б.С., Лихачев В.А., Мещеряков Ю.И. // ФММ. 1980. Т. 49. Вып. 5. С. 1032-1038.

[13] Манджавидзе А.Г., Барнов В.А., Соболевская С.В., Маргвелашвили О.В. // ЖТФ. 2006. Т. 76. Вып. 5. C. $131-133$. 